\title{
Serum-Free Media and the Immunoregulatory Properties of Mesenchymal Stem Cells In Vivo and In Vitro
}

\author{
Mei Wua Zhi-Bo Han ${ }^{b, c}$ Jun Feng Liuc You Wei Wang ${ }^{c}$ Jian Zhong Zhang ${ }^{c}$ \\ Chun Tuan Lia Peng Liang Xin ${ }^{\mathrm{a}}$ Zhong Chao Han ${ }^{\mathrm{b}, \mathrm{c}}$ Xiong Peng Zhu ${ }^{\mathrm{a}}$ \\ aDepartment of Hematology, First Hospital of Quanzhou Affiliated to Fujian Medical University,

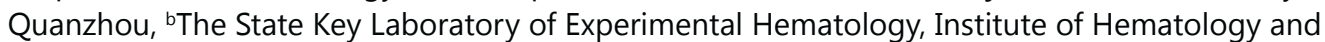 \\ Hospital of Blood Diseases, Chinese Academy of Medical Sciences and Peking Union Medical College, \\ 'National Stem Cell Engineering Research Center, TEDA, Tianjin, China
}

\section{Key Words}

Mesenchymal stem cells • Umbilical cord • Serum-free media • Immunomodulation

\begin{abstract}
Background: Mesenchymal stem cells are capable of self-renewal and multi-lineage differentiation. They are used extensively to treat several diseases. Traditionally, mesenchymal stem cells are cultured in serum-containing media, typically supplemented with fetal bovine serum (FBS). However, the variability of FBS is likely to skew experimental results. Although serumfree media used to expand mesenchymal stem cells has facilitated remarkable achievements, immunomodulation of these cells in under serum-free conditions is poorly understood. We hypothesized that mesenchymal stem cells expanded in serum-free media will retain powerful immunoregulatory functions in vitro and in vivo. Design and Methods: Immunosuppressive activity and the immunomodulatory cytokines produced by mesenchymal stem cells in serum-free media were characterized in vitro. Immunomodulation by serum-free mesenchymal stem cell expansion in monocrotaline-induced pulmonary hypertension was explored in vivo. Results: Similar to cells in serum-containing media, mesenchymal stem cells expanded in serum-free media inhibited proliferation and apoptosis of $C D 4^{+} T$ cells. They also exhibited strong immunosuppressive activities and secreted high levels of immunomodulatory cytokines such as PGE2, IDO1, COX2, IL-6, and IL-1 $\beta$, but not HGF. On the other hand, growth of mesenchymal stem cells in serum-free media attenuated pulmonary vascular remodeling and inhibited mRNA expression of proinflammatory cytokines TNF- $\alpha$, IFN- $\gamma$, IL-6, IL-1 $\beta$, and IL-18. Conclusions: Mesenchymal stem cells in serum-free media maintained powerful immunomodulatory function in vitro and in vivo; serum-free media may replace serum-containing media for basic research and clinical applications.




\section{Cellular Physiology and Biochemistry}

Cell Physiol Biochem 2014;33:569-580

\begin{tabular}{l|l}
\hline DOI: $10.1159 / 000358635$ & (C) 2014 S. Karger AG, Basel
\end{tabular}

Wu et al.: Serum-Free Media and the Immunoregulatory Properties of Mesenchymal Stem Cells

\section{Introduction}

Mesenchymal stem cells (MSCs) are a rare population of multipotent progenitor cells. The International Society for Cellular Therapy has defined MSCs as plastic-adherent; positive for expression of surface markers CD73, CD90, and CD105; absence of hematopoietic surface markers CD14, CD11b, CD19, CD34, CD45, and HLA-DR; and differentiation into osteoblasts, adipocytes, and chondroblasts [1]. MSCs have been isolated from bone marrow, adipose tissue, muscle, synovial membrane, umbilical cord, and cord blood [2-7]. Although MSCs were first identified in bone marrow, only 1-10 MSCs are found in $10^{6}$ bone marrow mononuclear cells [8-10]. Umbilical cord-derived mesenchymal stem cells (UC-MSCs) are a more promising source for their availability, low immunogenicity, and ease of collection [11].

MSCs are widely studied for their application in the treatment of diseases, including immune disorders such as graft-versus-host disease [12], experimental autoimmune encephalomyelitis [13], rheumatoid arthritis [14], and Crohn's disease [15]. In vitro expansion of MSCs is typically performed in traditional media containing fetal bovine serum, although the additive is ill-defined and highly variable, thus hampering basic and clinical MSC research. Serum free medium (SFM) is now being used to achieve better results. Dendritic cells grown in SFM strongly express activation markers and unusual surface markers [16]. Culturing MSCs in medium supplemented with human platelet lysate increases growth rate while preserving the MSC phenotype and differentiation capacity [17]. MSCs cultured in SFM supplemented with recombinant human platelet-derived growth factor-BB, basic fibroblast growth factor, and transforming growth factor (TGF)- $\beta 1$ yielded results similar to traditional culture medium in primary cell isolation, multipassage expansion, mesoderm differentiation, phenotype, and gene expression [18]. Immunomodulation of MSCs in SFM remains unknown. In this study, MSCs in SFM suppressed IFN- $\gamma$, TNF- $\alpha$, IL-21, IL-22, and IL-26 expression; activated secretion of immunomodulatory cytokines such as PGE2, COX2, ID01, and IL-6; and provided strong in vitro immunomodulation.

\section{Materials and Methods}

Isolation and expansion of UC-MSCS

Umbilical cords were obtained from local maternity hospitals with maternal informed consent. Human tissue collection for research was approved by the institutional review board of the Chinese Academy of Medical Science and Peking Union Medical College. Isolation of human umbilical cord mesenchymal stem cells (UC-MSCs) was performed as described [7]. Cells were plated in T75 cell culture flasks with DMEM/F12 medium (Hyclone) containing 10\% fetal bovine serum (NZORIGIN), $2 \mathrm{mM}$ glutamine, $100 \mathrm{U} / \mathrm{mL}$ penicillinstreptomycin, and $10 \mathrm{ng} / \mathrm{mL}$ epidermal growth factor (Peprotech), and maintained at $37^{\circ} \mathrm{C}$ in humidified $5 \% \mathrm{CO}_{2}$. The medium was exchanged and non-adherent cells were removed after 3 days.

\section{UC-MSCs expansion in SFM}

UC-MSCs culture medium was exchanged for SFM with MSCGM-CD (LONZA) at passage 3 (P3). UCMSCs expanded in serum-containing media (SCM) and SFM at P8-10 were preplated and irradiated (30 Gy).

Immunophenotype analysis by flow cytometry

UC-MSCs were collected and stained with PE-conjugated antibody against CD29, CD44, CD73, CD90, and CD105, or FITC-conjugated antibody against CD34. The isotype-matched immunoglobulins IgG1-PE and IgG1-FITC were used as negative controls. Antibodies were purchased from BD Pharmingen and used according to manufacturer protocols. Cells were analyzed by flow cytometry in a FACSCalibur with CellQuest software (Becton Dickinson).

\section{UC-MSCs differentiation and staining assays}

UC-MSCs were plated in 24 -well plates at $2 \times 10^{4}$ cells/well. The medium was exchanged with specific induction medium after 24 h. Osteogenic and adipogenic induction media were purchased from Sigma. 


\section{Cellular Physiology and Biochemistry}

Cell Physiol Biochem 2014;33:569-580

\begin{tabular}{l|l}
\hline DOI: $10.1159 / 000358635$ & (c) 2014 S. Karger AG, Basel
\end{tabular}

www.karger.com/cpb

Wu et al.: Serum-Free Media and the Immunoregulatory Properties of Mesenchymal Stem Cells

Table 1. Primers for real-time PCR

\begin{tabular}{ll}
\hline Human HPRT & forward:5'-CGTCGTGATTAGCGATGATGAAC-3' \\
Human HPRT & reverse:5'-TCACTAATGACACAAACGTGATTC-3' \\
Human ID01 & forward: 5'-AGACTGCTGGTGGAGGACATG-3' \\
Human ID01 & reverse: 5'-AAAGGACAAACTCACGGACTG-3' \\
Human COX2 & forward: 5'-ACTCTGGCTAGACAGCGTAA-3' \\
Human COX2 & reverse: 5'-ACCGTAGATGCTCAGGGAC-3' \\
Human IL-1 $\beta$ & forward: 5'-AGCTACGAATCTCCGACCAC-3' \\
Human IL-1 $\beta$ & reverse: 5'-CGTTATCCCATGTGTCGAAGAA-3' \\
Human IL-6 & forward: 5'-CCACACAGACAGCCACTCAC-3' \\
Human IL-6 & reverse: 5'-CCAGATTGGAAGCATCCATC-3' \\
Human HGF & forward:5'-CTCTGGTTCCCCTTCAATAG-3' \\
Human HGF & reverse:5'-CTGTAGGTCTTTACCCGATAG-3' \\
Human IFN- $\gamma$ & forward: 5'-GAGTGTGGAGACCATCAAGGAAG-3' \\
Human IFN- $\gamma$ & reverse: 5'-TGAGTTCATGTATTGCTTTG-3' \\
Human TNF- $\alpha$ & forward: 5'-CGAGTGACAAGCCTGTAGC-3' \\
Human TNF- $\alpha$ & reverse: 5'-GGTGTGGGTGAGGAGCACAT -3' \\
Human IL-21 & forward: 5'-GCAGGGAGAAGACAGAAACA-3' \\
Human IL-21 & reverse: 5'-GGAATCTTCACTTCCGTGTG-3' \\
Human IL-22 & forward: 5-ACAACACAGACGTTCGTCTCATTG-3' \\
Human IL-22 & reverse: 5'-GAACAGCACTTCTTCAAGGGTGA-3' \\
Human IL-26 & forward:5'-TTTGAGGTGTGGGTTGCTGTTA-3' \\
Human IL-26 & reverse:5'-TCAACAGCTTGGGACAATGTTC-3' \\
Rat GAPDH & forward: 5'-CCATTCTTCCACCTTTGATGCT-3' \\
Rat GAPDH & reverse: 5'-TGTTGCTGTAGCCATATTCATTGT-3' \\
Rat IFN- $\gamma$ & forward: 5'-CAGGCCATCAGCAACAACATA-3' \\
Rat IFN- $\gamma$ & reverse: 5'-TGGGTTGTTCACCTCGAACTT-3' \\
Rat TNF- $\alpha$ & forward: 5'-TCCCAGAGACTGTTCATGGT-3' \\
Rat TNF- $\alpha$ & reverse: 5'-TATCTGTGTGCACTTCGGTG 3' \\
Rat IL-1 $\beta$ & forward: 5'-TCCTCTGTGACTCGTGGGAT-3' \\
Rat IL-1 $\beta$ & reverse: 5'-TCAGACAGCACGAGGCATTT-3' \\
Rat IL-6 & forward: 5'-CCCAACTTCCAATGCTCTCCT-3' \\
Rat IL-6 & reverse: 5'-GGTTTGCCGAGTAGACCTCA-3' \\
Rat IL-18 & forward: 5'-AAGGATGTCTACCCTCTCCTGT-3' \\
Rat IL-18 & reverse: 5'-TTGTGTCCTGGCACACGTT-3' \\
\hline
\end{tabular}

During differentiation, the medium was replaced every 3 to 4 days. Atter 3 weeks induction, cells were stained with Oil Red $\mathrm{O}$ and alizarin red S solution, washed with distilled water, and visualized.

\section{Preparation of human $C D 4^{+} T$ cells}

Human cord blood mononuclear cells were isolated by Ficoll-Paque (Axis-Shield) density gradient centrifugation from the cord blood of healthy volunteers. CD4 ${ }^{+} \mathrm{T}$ cells were purified with magnetic MicroBead kits (Miltenyi Biotec) according to manufacturer protocols. Isolated CD4+T cell purity was $>95 \%$ (data not shown).

Coculture of CD $4^{+}$T cells and UC-MSCs

UC-MSCs were preplated and allowed to adhere for $18 \mathrm{~h}$ at $37^{\circ} \mathrm{C}$; CD4 ${ }^{+} \mathrm{T}$ cells were stimulated with phytohemagglutinin (PHA, Sigma, $10 \mu \mathrm{g} / \mathrm{mL}$ ) and IL-2 (Peprotech, $10 \mathrm{ng} / \mathrm{mL}$ ) were added at a ratio of 1:10 for $72 \mathrm{~h}$.

\section{Cell proliferation assay}

Cell proliferation was measured with an MTS kit according to manufacturer protocols (Promega). After 72-h culture, $\mathrm{CD} 4^{+} \mathrm{T}$ cells were collected and added to a new culture plate. MTS reagent (15 $\left.\mu \mathrm{l}\right)$ was added and incubated at $37^{\circ} \mathrm{C}$ for $4 \mathrm{~h}$. Supernatants were collected and absorbance was measured at $490 \mathrm{~nm}$ on a BioTek reader (BIO-RAD).

Total RNA extraction, reverse transcription, and real-time PCR

RNA was extracted with the E.Z.N.A. Total RNA Kit I (Omega Bio-Tek). cDNA synthesis was performed with the MLV RT kit (Invitrogen) for $50 \mathrm{~min}$ at $37^{\circ} \mathrm{C}$ in the presence of oligo-dT primer. PCR was performed with Platinum ${ }^{\circledR}$ SYBR ${ }^{\circledR}$ Green qPCR SuperMix-UDG w/ROX on an Applied Biosystems 7300 Real-Time PCR System. Primers are listed in Table 1 . PCR cycling conditions were $95^{\circ} \mathrm{C}$ for $2 \mathrm{~min}, 95^{\circ} \mathrm{C}$ for $15 \mathrm{~s}$, and $60^{\circ} \mathrm{C}$ for $30 \mathrm{~s}$ for 40 cycles. Cytokine transcripts were quantified by the $\Delta \Delta \mathrm{C}_{\mathrm{t}}$ method. 


\section{Cellular Physiology

Cell Physiol Biochem 2014;33:569-580

Wu et al.: Serum-Free Media and the Immunoregulatory Properties of Mesenchymal Stem Cells

Cytokine secretion and enzyme-linked immunosorbent assay

Cell free supernatants, plasma, and lung homogenate were collected and stored at $-80^{\circ} \mathrm{C}$. Cytokine concentrations were measured by enzyme-linked immunosorbent assay (ELISA). ELISA assay kits for

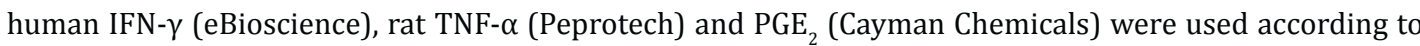
manufacturer protocols.

\section{Apoptosis and flow cytometry}

Cells were harvested and apoptosis was measured with a kit (Sungene). Briefly, cells were suspended in binding buffer and AnnexinV-PE and 7-AAD were added; flow cytometry was performed immediately.

\section{Experimental animals}

Animal protocols were approved by the Animal Care and Use Committee of the Chinese Academy of Medical Science and Peking Union Medical College. Animal experiments were performed according to the National Institutes of Health Guide for the Care and Use of Laboratory Animals [19]. Female Sprague-Dawley (SD) rats (aged 6-8weeks, weighing 200g) were purchased from the Laboratory Animals Center of Chinese Academy of Medical Science and Peking Union Medical College. The pulmonary arterial hypertension (PAH) model was established as described [20]. The rats were randomly divided into four groups as follows: Control group ( $n=6)$, subcutaneous injection of normal saline; PAH group $(n=6)$, subcutaneous injection of monocrotaline (Sigma); SCM group $(\mathrm{n}=6)$, caudal vein injection of UC-MSCs in SCM $\left(1 \times 10^{6} /\right.$ cells $)$ after 5 days of monocrotaline injection; SFM group $(n=6)$, caudal vein injection of UC-MSCs in SFM $\left(1 \times 10^{6} /\right.$ cells $)$ after 5 days of monocrotaline injection.

\section{Histology}

Three weeks after injection of monocrotaline, rats were anesthetized by $20 \%$ chloral hydrate. Lung tissues were removed, fixed with $10 \%$ paraformaldehyde, embedded in paraffin, and cut into $4-5 \mu \mathrm{m}$ sections. The sections were stained with hematoxylin and eosin and observed by light microscopy $(\times 400)$. Wall thickness $(\mathrm{WT}, \%)=[($ medial thickness $\times 2) /$ external diameter $] \times 100$ was used to evaluate the medial wall thickness of pulmonary arterioles.

\section{Statistical analysis}

The SPSS 17.0 software package was used to analyze data. Data are presented as mean \pm SD. Comparisons were performed by Student's unpaired t-test or one-way ANOVA. Survival data were analyzed by Kaplan-Meier method with log-rank test. P values less than 0.05 were considered significant.

\section{Results}

The characteristics of UC-MSCS in SFM

UC-MSCs in SFM expanded in large quantities and tended to be more fibroblast-like in comparison to cells cultured in SCM (Fig. 1). To determine whether UC-MSCs in SFM retained differentiation potential in vitro, we induced P9 UC-MSCs in SFM into osteoblasts and adipocytes and observed the results by alizarin red $S$ and oil red $O$ staining. The results showed UC-MSCs in SFM retained the capacity for osteoblast and adipocyte differentiation; indeed the lipid droplets were larger in adipocytes from SFM versus SCM culture. Flow cytometry showed that UC-MSCs in SFM expressed higher levels of CD29, CD44, CD73, CD90, and CD105 and lower levels of CD34. Expression of these surface markers was similar in SCM ( $p>0.05)$. Thus, UC-MSCs in SFM retained their morphology, immunophenotype, and differentiation characteristics.

\section{UC-MSC proliferation suppression in SFM}

We examined the effect of human UC-MSCs in SFM on CD4+T cells in vitro. CD4+T cells were treated with UC-MSCs in SFM or SCM at a ratio of 1:10 for $72 \mathrm{~h}$ in the absence or presence of stimuli (PHA and IL-2). CD4 ${ }^{+}$T cells could not proliferate without stimulation (Fig. 2A). CD4 ${ }^{+}$T cells grew quickly and in clusters upon activation (Fig. 2B). However, when 


\section{Cellular Physiology and Biochemistry}

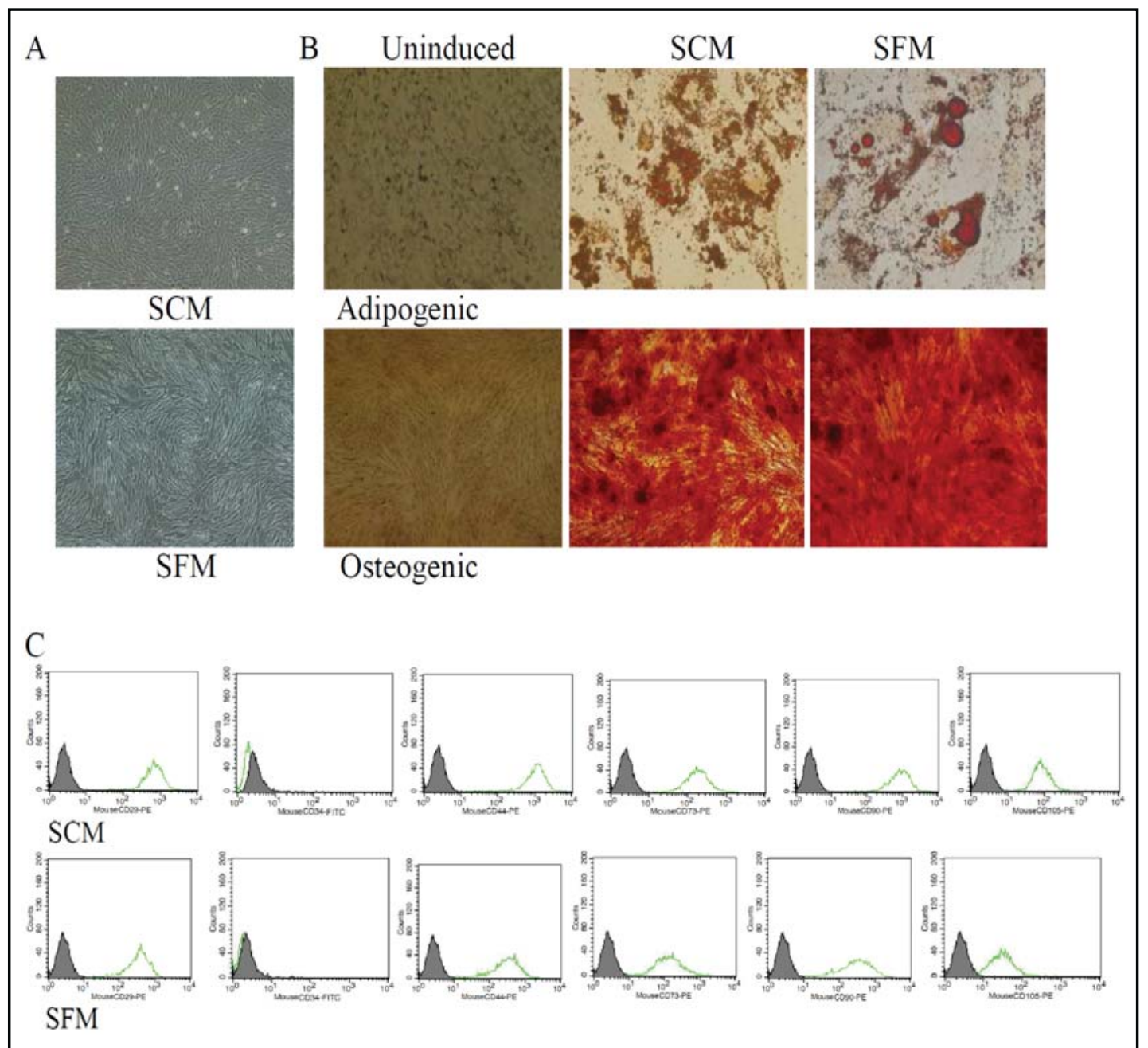

Fig. 1. The characteristics of UC-MSCs in SFM. (A) Morphologies of UC-MSCs in SCM and SFM. (B) UC-MSCs in SCM and SFM were plated in 24-well plates at a density of $2 \times 10^{4}$ cells/well. After 24 hours, the medium was changed with specific induction medium for 3 weeks. Adipogenic and osteogenic differentiation were observed by oil red 0 staining (magnification: 200×) and Alizarin red S staining (magnification: 40×), respectively; (C) Immunophenotypes of UC-MSCs in SCM and SFM.

cocultured with UC-MSCs in SCM or SFM in the presence of stimuli, the CD4 ${ }^{+}$T cells grew in a spreading pattern (Fig. 2C, D). CD4+T cell proliferation was evaluated by MTS (Fig. 2E), which showed significantly stronger growth in activated cultures. When cocultured with UCMSCSs in SCM or SFM, growth rate decreased in comparison to activated CD4 $4^{+} \mathrm{T}$ cells alone $(p<0.001)$; there was no significant difference between SCM and SFM in this experiment ( $p>0.05$ ). We conclude that UC-MSCs in SFM also inhibit activated CD $4^{+} \mathrm{T}$ cell proliferation in vitro.

\section{Immunomodulation of UC-MSCS in SFM}

We then compared the immunosuppressive capacities of UC-MSCs in SCM and SFM by measuring IFN- $\gamma$ production. As shown in Figure $3 \mathrm{~A}, \mathrm{CD}^{+} \mathrm{T}$ cells secreted higher levels of IFN- $\gamma$ in the presence of PHA and IL- 2 stimulation; however, IFN- $\gamma$ production was reduced in $\mathrm{CD} 4^{+} \mathrm{T}$ cell coculture with UC-MSCs in SCM or SFM. The degree of IFN- $\gamma$ inhibition by UC-MSCs in SFM differed slightly but not significantly from SCM ( $p>0.05)$. Furthermore, although UC- 


\section{Cellular Physiology $\quad$ Cell Physiol Biochem 2014;33:569-580 \\ \begin{tabular}{ll|l} 
and Biochemistry & $\begin{array}{l}\text { DOI: 10.1159/000358635 } \\
\text { Publisned onIIne: February 25, } 2014\end{array}$ & $\begin{array}{l}\text { C 2014 S. Karger AG, Basel } \\
\text { www.karger.com/cpb }\end{array}$ \\
\cline { 2 - 3 } Wu et al.: Serum-Free Media and the Immunoregulatory Properties of Mesenchymal
\end{tabular} Stem Cells}

Fig. 2. UC-MSCs in SFM suppress proliferation of activated purified umbilical cord blood CD4+T cells. Purified umbilical cord blood CD4 ${ }^{+} \mathrm{T}$ cells $\left(3 \times 10^{4}\right)$ were treated with $3 \times 10^{3}$ irradiated UC-MSCs/well in a 96well plate for $72 \mathrm{~h}$ in the absence or presence of stimuli (PHA and IL-2). (A) CD4+T cells without UC-MSCs in the absence of stimuli; (B) $\mathrm{CD}^{+} \mathrm{T}$ cells without UCMSCs in the presence of stimuli; (C) $\mathrm{CD}^{+}{ }^{+} \mathrm{T}$ cells with UC-MSCs in SCM in the presence of stimuli; (D) $\mathrm{CD}^{+} \mathrm{T}$ cells with UC-MSCs in SFM in the presence of stimuli; Magnification: 40× (E) Proliferation was evaluated by MTS. Data represent the mean \pm SD of three independent experiments, each performed in triplicate. *** $\mathrm{P}<0.001$, \# $\mathrm{P}>0.05$.
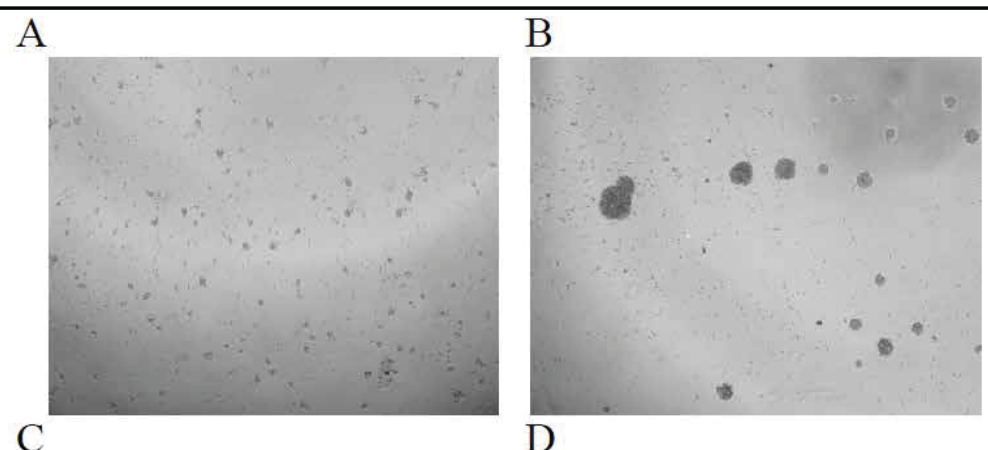

D
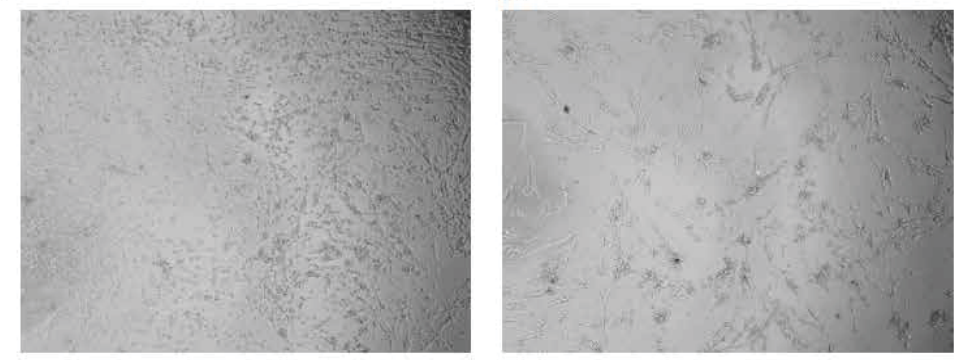

E

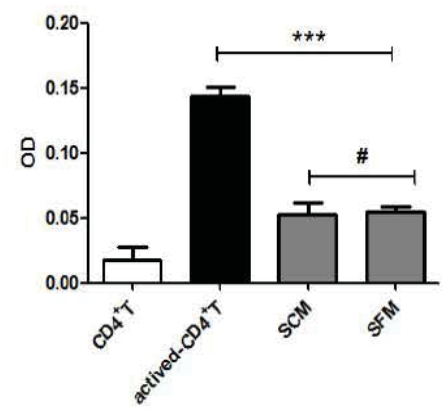

MSC cultures in both media showed reduced $\mathrm{CD} 4^{+} \mathrm{T}$ cell expression of intracellular cytokines IFN- $\gamma$, TNF-a, IL-21, IL-22, and IL-26, the difference was not significant ( $p>0.05$ ) (Fig. 3BF). MSCs mediate immunoregulation via cell-cell contact or soluble factors [21]. Therefore, we compared UC-MSCs cultured in different media for secretion of soluble factors including prostaglandin E2 (PGE2), indoleamine 2,3-dioxygenase 1 (ID01), hepatocyte growth factor (HGF), interleukin 6 (IL-6), and other immunoregulatory factors such as cyclooxygenase-2 (COX2) and interleukin 1 $\beta$ (IL-1 $\beta$ ) (Fig. 3G-L). PGE2 production by UC-MSCs in SCM or SFM increased dramatically, but did not differ between groups. In addition, transcript levels of COX2, ID01, IL-1 $\beta$, and IL-6 in SFM-cultured UC-MSCs were similar to those in SCM ( $p>0.05)$, with the exception of HGF ( $\mathrm{p}<0.05$ ). Thus, compared with UC-MSCs in SCM, those in SFM also had strong immunosuppressive activities and produced high levels of immunomodulatory factors.

\section{Apoptosis}

We used PE-anti-Annexin V and 7-AAD double staining to evaluate the effect of UC-MSCs in SFM on CD 4 ${ }^{+}$T cell apoptosis. As shown in Figure 4, there were large quantities of Annexin $\mathrm{V}^{+}$and $7-\mathrm{AAD}^{+} \mathrm{CD} 4^{+} \mathrm{T}$ cells in cultures stimulated with PHA and IL-2. However, when CD4+T cells were cocultured with UC-MSCs in SCM or SFM, apoptosis was significantly reduced ( $40.24 \pm 4.43 \%$ vs. $28.24 \pm 3.86 \%$ and $20.45 \pm 2.81 \%$ ) (p < 0.001). CD4+T-cell apoptosis was lower in coculture with UC-MSCs expanded in SFM than with UC-MSCs expanded in SCM ( $p$ < 0.05).These data suggest UC-MSCs in SFM seem to be more capable of suppressing CD $4^{+} \mathrm{T}$-cell apoptosis. 
Wu et al.: Serum-Free Media and the Immunoregulatory Properties of Mesenchymal Stem Cells

A

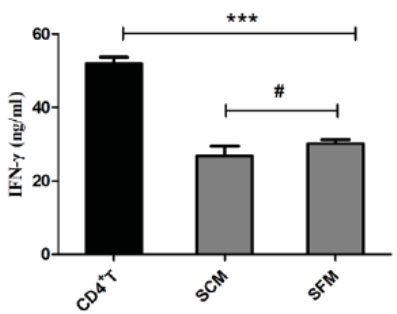

D

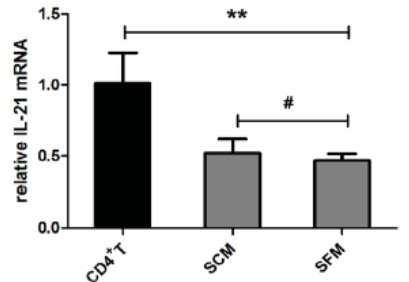

G

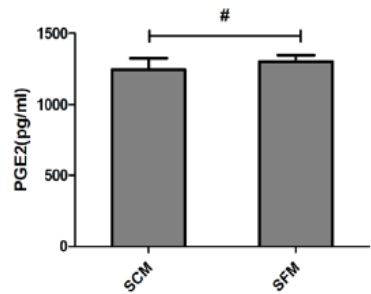

J

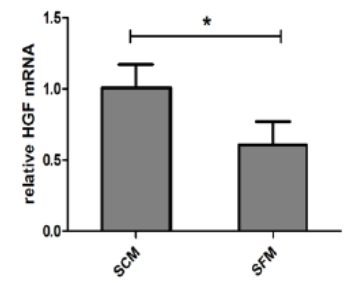

B

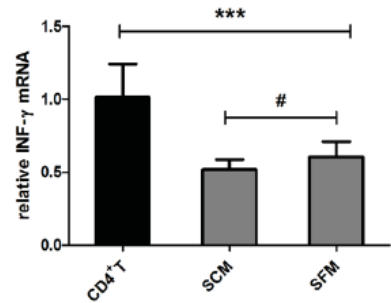

E

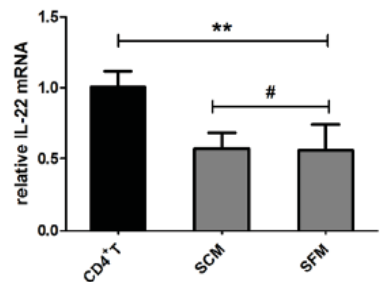

$\mathrm{H}$

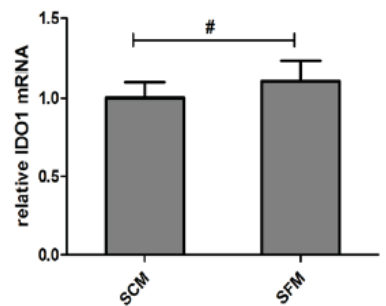

K

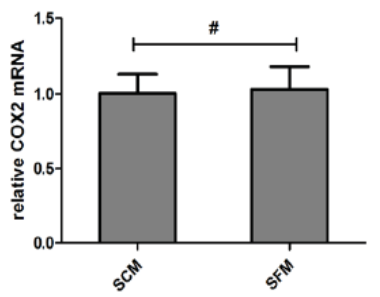

C

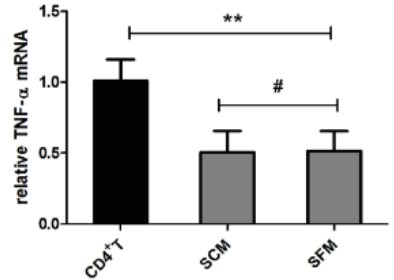

F

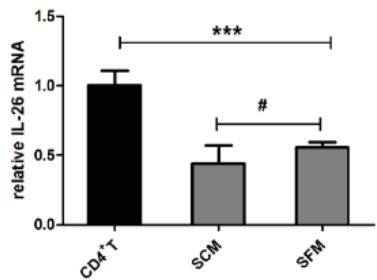

I

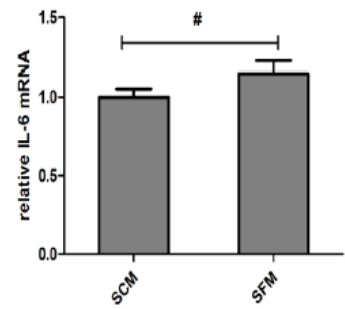

L

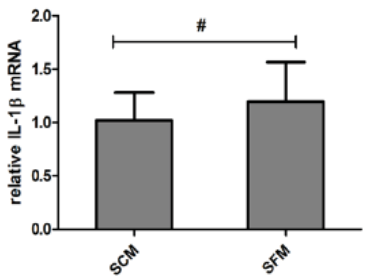

Fig. 3. Immunomodulation of UC-MSCs in SFM (A-L). Irradiated UC-MSCs $\left(3 \times 10^{3} /\right.$ well) in SCM and SFM were incubated in 96-well plates for $18 \mathrm{~h}$, then CD4+T cells at a ratio of 1:10 were added for $72 \mathrm{~h}$. The concentrations of IFN- $\gamma$ and PGE2 were determined by ELISA. Relative mRNA expression was analyzed by real-time PCR. Results are presented as mean \pm SD of a single experiment, each performed in triplicate. *** $\mathrm{P}<0.001,{ }^{* *} \mathrm{P}<0.01,{ }^{*} \mathrm{P}<0.05$, \# $\mathrm{P}>0.05$.

\section{UC-MSCs in SFM and pulmonary arterial hypertension}

To evaluate the immunomodulation properties of SFM-expanded UC-MSCs expanded in vivo, we used them to treat PAH induced by monocrotaline. Pulmonary arterial walls thickened and the arterial lumen became stenotic after monocrotaline injection in comparison to the control group. When rats were administered transplants of $10^{6} \mathrm{UC}-\mathrm{MSCs}$ in SCM or SFM via the caudal vein after 5 days of monocrotaline injection, the pulmonary arterial walls were not thicker than in the PAH group (Fig. 5A). In addition, Wall thickness was calculated to compare pulmonary arterial wall changes between groups (Fig. 5B). Histology 


\section{Cellular Physiology \\ and Biochemistry}

Cell Physiol Biochem 2014;33:569-580

\begin{tabular}{l|l}
\hline DOI: $10.1159 / 000358635$ & (c) 2014 S. Karger AG, Basel
\end{tabular}

Wu et al.: Serum-Free Media and the Immunoregulatory Properties of Mesenchymal Stem Cells

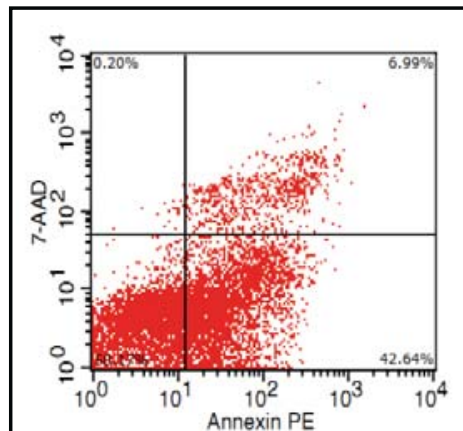

$\mathrm{CD} 4^{+} \mathrm{T}$

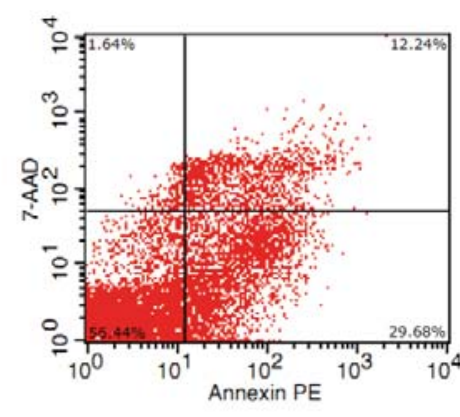

SCM

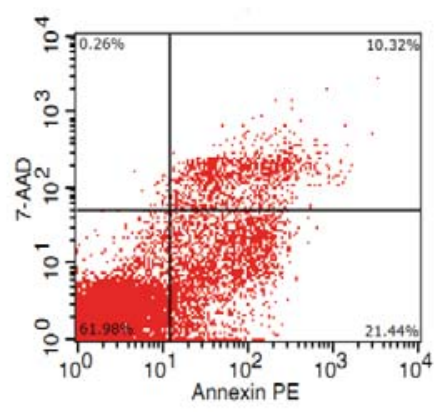

SFM

Fig. 4. UC-MSCs in SFM suppress apoptosis of activated CD4 ${ }^{+} \mathrm{T}$ cells. Irradiated UC-MSCs (10 $/$ well) in SCM and SFM were incubated for $18 \mathrm{~h}$ in 24 -well plates; CD4 ${ }^{+} \mathrm{T}$ cells $\left(10^{6} /\right.$ well) were added and incubated for 72 h. CD4 ${ }^{+}$T cells were harvested and washed twice in cold PBS, then stained with PE-anti-Annexin V, 7-AAD and analyzed by flow cytometry. Data represent the mean \pm SD of three independent experiments, each performed in triplicate.

revealed that wall thickness in the PAH group $(31.68 \pm 2.26 \%)$ was larger than in the SCM or SFM groups $(17.72 \pm 1.32 \% ; 18.43 \pm 1.58 \%$; $\mathrm{p}<0.001)$, and there was no difference between pulmonary arterial walls transplanted with UC-MSCs in SCM and SFM ( $p>0.05)$. Numerous CM-Dil labeled UC-MSCs were observed in the lung tissues of rats transplanted with UCMSCs (Fig. 5C). TNF- $\alpha$ levels in peripheral blood and lung tissues of PAH rats in the SCM and SFM groups decreased almost $3-$ and 2 -fold, respectively $(\mathrm{p}<0.001)$. In addition, transcript expression of TNF- $\alpha$, IFN- $\gamma$, IL-1 $\beta$, IL- 6 , and IL-18 in lung tissues of rats treated with UCMSCs expanded in SCM or SFM were also down-regulates in comparison to the PAH group (Fig. 5D,5E). Cytokine expression did not differ between the SCM and SFM groups (P >0.05). Finally, 4 of the 24 animals died at 3 weeks after injection of monocrotaline, including 2 in PAH group, 1 in SCM group and 1 in SFM group, the survival rate of four groups were $100 \%$, $66.7 \%, 83.3 \%, 83.3 \%$, respectively ( $\mathrm{p}<0.05$ ). The sacrifice time of PAH group were 18th, 20th day, SCM group 13th day and SFM group 8th day, respectively. Therefore, these results demonstrated that UC-MSCs in SFM can attenuate monocrotaline-induced PAH and increase survival rates as same as those in SCM.

\section{Discussion}

Inthisstudy, we demonstrated fact that MSCs from human umbilical cord in SFM possessed strong immunomodulation capacity and produced higher levels of immunoregulatory factors in vitro. We also found that UC-MSCs expanded in SFM improved pulmonary vascular remodeling and down-regulated TNF- $\alpha$ levels in monocrotaline-induced PAH.

Although they retained many of the biological characteristics of UC-MSCs grown in SCM, cells grown in SFM were slightly different. UC-MSCs grown in SFM were more fibroblastlike, passages decreased significantly, and growth was slower, but the number of cells was sufficient. They were positive for CD29, CD44, CD73, CD90, and CD105 but negative for CD34, and retained the ability to differentiate into osteoblasts and adipocytes, consistent with the standard definition of MSCs [1]. MSCs have many uses because they modulate the functions of immune cells, including T cells [22], B cells [23], NK cells [24], dendritic cells [25], and neutrophils [26]. For example, MSCs suppress T-cell proliferation, shift Th1 cells toward Th2 cells [12], and inhibit differentiation of the Th17 subtype of $C D 4^{+} \mathrm{T}$ cells [27]. Furthermore, 
 \\ Wu et al.: Serum-Free Media and the Immunoregulatory Properties of Mesenchymal Stem Cells}

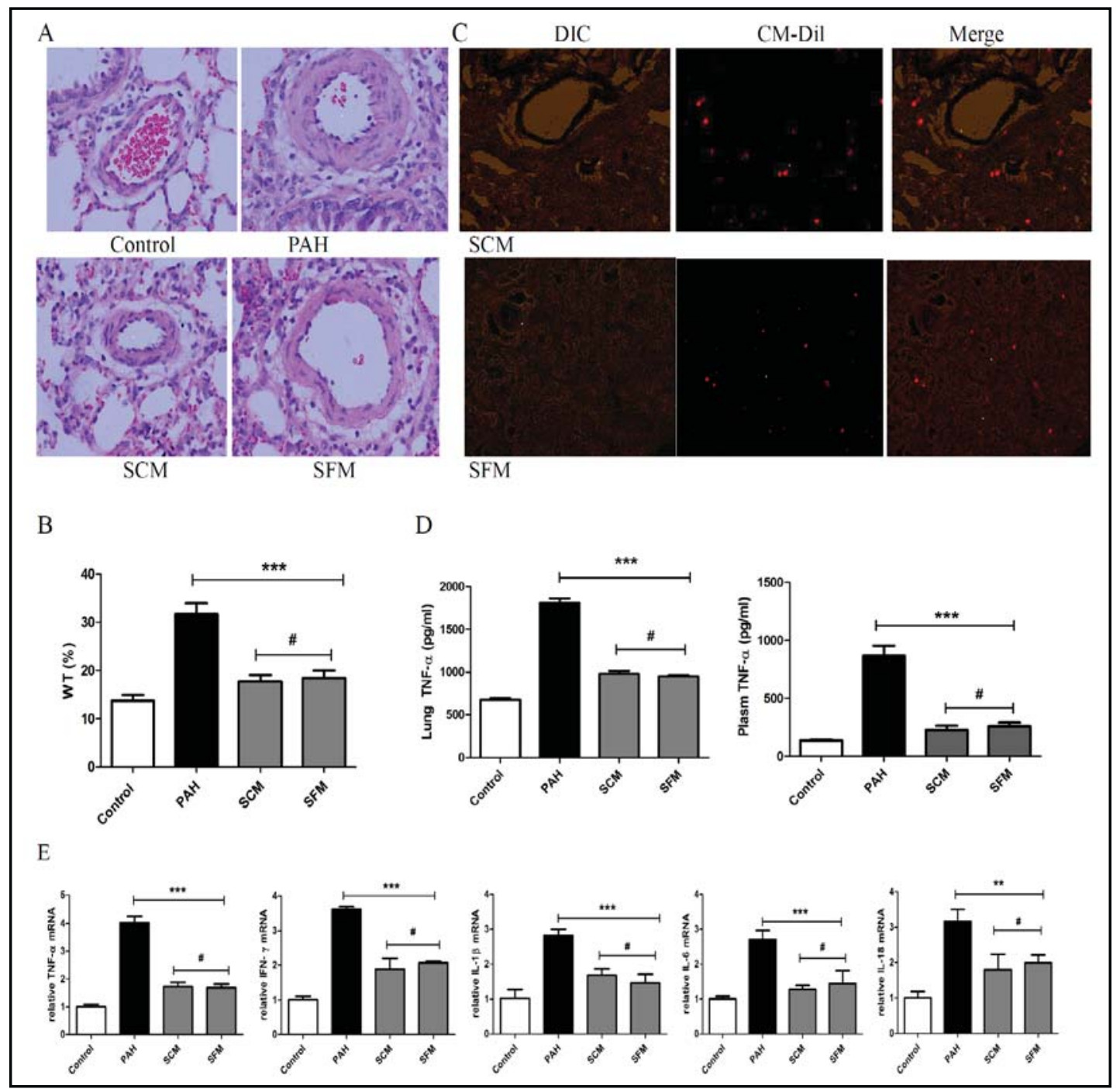

Fig. 5. Effect of UC-MSCs in SFM on PAH. PAH was induced by monocrotaline. UC-MSCs in SCM or SFM were transplanted on the fifth day of monocrotaline injection; (A) structural alterations of pulmonary artery walls were determined by hematoxylin and eosin staining after 3 weeks of monocrotaline injection; Magnification: 200x; (B) Wall thickness (WT, \%) was used to evaluate medial wall thickness of the pulmonary arteriole; (C) The distributions of CM-Dil labelled hUC-MSCs in lung tissues. DIC, differential interference contrast ; CM-Dil, CM-Dil labelled hUC-MSCs in SCM and SFM;Merge, merge of DIC and CM-Dil labelled hUCMSCs in SCM and SFM; (Magnification: 200×).(D)TNF- $\alpha$ levels in peripheral blood and lung tissues were measured by ELISA; (E) TNF- $\alpha$, IFN- $\gamma$, IL-1 $\beta$, IL- 6 and IL-18 mRNA expression in lung tissues was determined by real-time PCR. Data represent the mean \pm SD of six independent experiments, each performed in triplicate. ${ }^{* * *} \mathrm{P}<0.001,{ }^{* *} \mathrm{P}<0.01, \# \mathrm{P}>0.05$.

MSCs support the proliferation and terminal differentiation of B cells [28]. MSCs significantly inhibit Th1 cell secretion of IFN- $\gamma$ and TNF- $\alpha$. In this study, proliferation of CD4+T cells was inhibited in coculture with UC-MSCs in SFM, and production of IFN- $\gamma$ decreased, similar to SCM. This phenomenon was also observed for other proinflammatory cytokines such as TNF- $\alpha$, IL-21, IL-22, and IL-26. UC-MSCs in SFM were also stronger suppressors of CD4+T cell apoptosis.

It is kown that MSCs play their immunomodulatory effects via cell-cell contact or soluble factors including nitric oxide [15], PGE2 [29], ID01 [30], TGF- $\beta 1$ [31], HGF [32], IL-6 [33], 


\section{Cellular Physiology

Cell Physiol Biochem 2014;33:569-580

Wu et al.: Serum-Free Media and the Immunoregulatory Properties of Mesenchymal Stem Cells

HLA-G [34], and IL-10 [35]. PGE2 is an important immunomodulatory factor that mediates immuno-inhibition through its four receptors (EP1-EP4) expressed on various cells [36] and suppresses Th1, CTL, and NK cell-mediated type-1 immunity [37]. In this study, we measured the expression of soluble factors (PGE2, IDO1, HGF, IL-6) and other immunomodulatory cytokines such as COX-2, and IL-1 $\beta$ by ELISA and real-time PCR and found no significant difference in UC-MSCs expanded in SCM or SFM. However, HGF expression was significantly lower in SFM than in SCM, a finding that conflicts with a previous report [38]. This discordance may be due to differences in media or the choice of MSCs.

$\mathrm{PAH}$ is a progressive disease characterized by the structural alterations of the pulmonary vasculature, leading to high pulmonary blood pressure [39]. The pathogenesis of PAH remains unclear, but proinflammatory cytokines such as TNF- $\alpha$, TGF- $\beta$, and IL- 6 are important factors in this condition. TNF- $\alpha$ and TGF- $\beta$ inhibition reverses the hemodynamic changes and pulmonary vascular remodeling in monocrotaline-induced PAH [40, 41]. Zhang et al. treated experimental PAH with bone marrow-derived MSCs and obtained similar results [42]. We used UC-MSCs expanded in SFM to treat PAH and observed a substantial reduction in the thickness of the pulmonary arterial wall. There were many CM-DiI UC-MSCs in the lung tissues of rats transplanted with UC-MSCs and levels of TNF- $\alpha$, IFN- $\gamma$, IL- $1 \beta$, IL- 6 , and IL18 in the lung tissues and peripheral blood were reduced. Most important, the survival rates of rats transplanted with UC-MSCs in SFM and SCM had increased significantly.

This is the first report to demonstrate that UC-MSCs in SFM retain powerful immunosuppressive activities in vivo and vitro, paving the way for improved basic and clinical studies of MSCs.

\section{Conflict of Interests}

The authors have no competing financial interests to declare.

\section{Acknowledgement}

The authors have no acknowledgements to report.

\section{References}

1 Dominici M, Le Blanc K, Mueller I, Slaper-Cortenbach, Marini F, Krause D, Deans R, Keating A, Prockop Di, Horwitz E: Minimal criteria for defining multipotent mesenchymal stromal cells. The International Society for Cellular Therapy position statement. Cytotherapy 2006;84:315-317.

-2 Friedenstein AJ, Petrakova KV, Kurolesova AI, Frolova GP: Heterotopic of bone marrow. Analysis of precursor cells for osteogenic and hematopoietic tissues. Transplantation 1968;62:230-247.

- 3 Hu Y, Liao L, Wang Q, Ma G, Jiang X, Zhao RC: Isolation and identification of mesenchymal stem cells from human fetal pancreas. J Lab Clin Med 2003;1415: 342-349.

4 Barry FP, Murphy JM. Mesenchymal stem cells: Clinical applications and biological characterization. Int J Biochem Cell Biol 2004;36:568-584.

5 in't Anker PS, Noort WA, Scherjon SA, Kleijburg-van der Keur C, Kruisselbrink AB, van Bezooijen RL, Beekhuizen W, Willemze R, Kanhai HH, Fibbe WE: Mesenchymal stem cells in human second-trimester bone marrow, liver, lung, and spleen exhibit a similar immunophenotype but a heterogeneous multilineage differentiation potential. Haematologica 2003;88:845-852.

6 Lee OK, Kuo TK, Chen WM, Lee KD, Hsieh SL, Chen TH: Isolation of multipotent mesenchymal stem cells from umbilical cord blood. Blood 2004;1035:1669-1675.

7 Lu LL, Liu YJ, Yang SG, Zhao QJ, Wang x, Gong W, Han ZB, Xu ZS, Lu YX, Liu D, Chen ZZ, Han ZC: Isolation and characterization of human umbilical cord mesenchymal stem cells with hematopoiesis-supportive function and other potentials. Haematologica 2006;918:1017-1026. 


\section{Cellular Physiology and Biochemistry}

Cell Physiol Biochem 2014;33:569-580

\begin{tabular}{l|l}
\hline DOI: $10.1159 / 000358635$ & C 2014 S. Karger AG, Basel \\
\hline
\end{tabular}

Wu et al.: Serum-Free Media and the Immunoregulatory Properties of Mesenchymal Stem Cells

8 Castro-Malaspina H, Gay RE, Resnick G, Kapoor N, Meyers P, Chiarieri D, McKenzie S, Broxmeyer HE, Moore MA: Characterization of human bone marrow fibroblast colony-forming cells (CFU-F) and their progeny. Blood 1980;562:289-301.

-9 Lazarus HM, Haynesworth SE, Gerson SL, Rosenthal NS, Caplan AI: Ex vivo expansion and subsequent infusion of human bone marrow-derived stromal progenitor cells (mesenchymal progenitor cells): implications for therapeutic use. Bone Marrow Transplant 1995;164:557-564.

10 Reyes M, Verfaillie CM: Characterization of multipotent adult progenitor cells, a subpopulation of mesenchymal stem cells. Annals N Y Acad Sci 2001;938:231-235.

11 Wang HW, Lin LM, He HY, You F, Li WZ, Huang TH, Ma GX, Ma L: Human umbilical cord mesenchymal stem cells derived from Wharton's jelly differentiate into insulin-producing cells in vitro. Chin Med J (Engl) 2011;12410:1534-1539.

12 Aggarwal S, Pittenger MF. Human mesenchymal stem cells modulate allogeneic immune cell responses. Blood 2005;1054:1815-1822.

-13 Zappia E, Casazza S, Pedemonte E, Benvenuto F, Bonanni I, Gerdoni E, Giunti D, Ceravolo A, Cazzanti F, Frassoni F: Mesenchymal stem cells ameliorate experimental autoimmune encephalomyelitis inducing T-cell anergy. Blood 2005;1065:1755-1761.

14 MacFarlane RJ, Graham SM, Davies PS, Korres N, Tsouchnica H, Heliotis M, Mantalaris A, Tsiridis E: Antiinflammatory role and immunomodulation of mesenchymal stem cells in systemic joint diseases: potential for treatment. Expert Opin Ther Targets 2013;173:243-254.

-15 Molendijk I, Duijvestein M, van der Meulen-de Jong AE, van Deen WK, Swets M, Hommes DW, Verspaget HW: Immunomodulatory effects of mesenchymal stromal cells in Crohn's disease. J Allergy(Cairo) 2012;2012:187408.

16 Kim SJ, Diamond B: Generation and maturation of bone marrow-derived DCs under serum-free conditions. J Immunol Methods 2007;3232:101-108.

17 Ben Azouna N, Jenhani F, Regaya Z, Berraeis L, Ben Othman T, Ducrocq E, Domenech J: Phenotypical and functional characteristics of mesenchymal stem cells from bone marrow: comparison of culture using different media supplemented with human platelet lysate or fetal bovine serum. Stem Cell Res Ther 2012;31:6.

18 Chase LG, Lakshmipathy U, Solchaga LA, Rao MS, Vemuri MC: A novel serum-free medium for the expansion of human mesenchymal stem cells. Stem Cell Res Ther 2010;11:8.

-19 Zuo XR, Wang Q, Cao Q Yu YZ, Wang H, Bi LQ Xie WP, Wang H: Nicorandil prevents right ventricular remodeling by inhibiting apoptosis and lowering pressure overload in rats with pulmonary arterial hypertension. PloS One 2012;79:e44485.

20 Gao H, Chen C, Huang S, Li B: Quercetin attenuates the progression of monocrotaline-induced pulmonary hypertension in rats.J Biomed Res 2012;262:98-102.

-21 Wang D, Chen K, Du WT, Han ZB, Ren H, Chi Y, Yang SG, Bayard F, Zhu D, Han ZC: CD14+ monocytes promote the immunosuppressive effect of human umbilical cord matrix stem cells. Exp Cell Res 2010;31615:2414-2423.

22 Glennie S, Soeiro I, Dyson PJ, Lam EW, Dazzi F: Bone marrow mesenchymal stem cells induce division arrest anergy of activated T cells. Blood 2005;1057:2821-2827.

-23 Corcione A, Benvenuto F, Ferretti E, Giunti D, Cappiello V, Cazzanti F, Risso M, Gualandi F, Mancardi GL, Pistoia V: Human mesenchymal stem cells modulate B-cell functions. Blood 2006;1071:367-372.

24 Spaggiari GM, Capobianco A, Becchetti S, Mingari MC, Moretta L: Mesenchymal stem cell-natural killer cell interactions: evidence that activated NK cells are capable of killing MSCs, whereas MSCs can inhibit IL-2induced NK-cell proliferation. Blood 2006;1074:1484-1490.

25 Dokic J, Tomic S, Markovic M, Milosavljevic P, Colic M: Mesenchymal stem cells from periapical lesions modulate differentiation and functional properties of monocyte-derived dendritic cells. Eur J Immunol 2013;437:1862-1872.

26 Duffy MM, Ritter T, Ceredig R, Griffin MD: Mesenchymal stem cell effects on T-cell effector pathways. Stem Cell Res Ther 2011;24:34.

27 Duffy MM, Pindjakova J, Hanley SA, McCarthy C, Weidhofer GA, Sweeney EM, English K, Shaw G, Murphy JM, Barry FP: Mesenchymal stem cell inhibition of T-helper 17 cell differentiation is triggered by cell-cell contact and mediated by prostaglandin E2 via the EP4 receptor. Eur J Immunol 2011;4110:2840-2851. 
Wu et al.: Serum-Free Media and the Immunoregulatory Properties of Mesenchymal Stem Cells

-28 Ji YR, Yang ZX, Han ZB, Meng L, Liang L, Feng XM, Yang SG, Chi Y, Chen DD, Wang YW: Mesenchymal stem cells support proliferation and terminal differentiation of B cells. Cell Physiol Biochem 2012;306:15261537.

29 Chen K, Wang D, Du WT, Han ZB, Ren H, Chi Y, Yang SG, Zhu D, Bayard F, Han ZC: Human umbilical cord mesenchymal stem cells hUC-MSCs exert immunosuppressive activities through a PGE2-dependent mechanism. Clin Immunol 2010;1353:448-458.

-30 Opitz CA, Litzenburger UM, Lutz C, Lanz TV, Tritschler I, Koppel A, Tolosa E, Hoberg M, Anderl J, Aicher WK: Toll-like receptor engagement enhances the immunosuppressive properties of human bone marrowderived mesenchymal stem cells by inducing indoleamine-2,3-dioxygenase-1 via interferon-beta and protein kinase R. Stem Cells 2009;274:909-919.

-31 Nemeth K, Keane-Myers A, Brown JM, Metcalfe DD, Gorham JD, Bundoc VG, Hodges MG, Jelinek I, Madala S, Karpati S: Bone marrow stromal cells use TGF-beta to suppress allergic responses in a mouse model of ragweed-induced asthma. Proc Natl Acad Sci USA 2010;10712:5652-5657.

-32 Di Nicola M, Carlo-Stella C, Magni M, Milanesi M, Longoni PD, Matteucci P, Grisanti S, Gianni AM: Human bone marrow stromal cells suppress T-lymphocyte proliferation induced by cellular or nonspecific mitogenic stimuli. Blood 2002;9910:3838-3843.

-33 Nauta AJ, Kruisselbrink AB, Lurvink E, Willemze R, Fibbe WE: Mesenchymal stem cells inhibit generation and function of both CD34+-derived and monocyte-derived dendritic cells. J Immunol 2006;1774:20802087.

-34 Selmani Z, Naji A, Gaiffe E, Obert L, Tiberghien P, Rouas-Freiss N, Carosella ED, Deschaseaux F: HLA-G is a crucial immunosuppressive molecule secreted by adult human mesenchymal stem cells. Transplantation 2009;879:S62-66.

-35 Liu WH, Liu JJ, Wu J, Zhang LL, Liu F, Yin L, Zhang MM, Yu B: Novel mechanism of inhibition of dendritic cells maturation by mesenchymal stem cells via interleukin-10 and the JAK1/STAT3 signaling pathway. PloS One 2013;81:e55487.

-36 Whiteside TL, Mandapathil M, Schuler P: The role of the adenosinergic pathway in immunosuppression mediated by human regulatory T cells (Treg). Curr Med Chem 2011;1834:5217-5223.

-37 Kalinski P: Regulation of immune responses by prostaglandin E2. J Immunol 2012;1881:21-28.

-38 Crapnell K, Blaesius R, Hastings A, Lennon DP, Caplan AI, Bruder SP: Growth, differentiation capacity, and function of mesenchymal stem cells expanded in serum-free medium developed via combinatorial screening. Exp Cell Res 2013;31910:1409-1418.

39 Ahn B, Empinado HM, Al-Rajhi M, Judge AR, Ferreira LF: Diaphragm atrophy and contractile dysfunction in a murine model of pulmonary hypertension. PloS One 2013;84:e62702.

\$0 Wang Q Zuo XR, Wang YY, Xie WP, Wang H, Zhang M: Monocrotaline-induced pulmonary arterial hypertension is attenuated by TNF-alpha antagonists via the suppression of TNF-alpha expression and NFkappaB pathway in rats. Vascul Pharmacol 2013;58:71-77.

-41 Megalou AJ, Glava C, Vilaeti AD, Oikonomidis DL, Baltogiannis GG, Papalois A, Vlahos AP, Kolettis TM: Transforming growth factor-beta inhibition and endothelin receptor blockade in rats with monocrotalineinduced pulmonary hypertension. Pulm Circ 2012; 24: 461-469.

-42 Zhang ZH, Lu Y, Luan Y, Zhao JJ: Effect of bone marrow mesenchymal stem cells on experimental pulmonary arterial hypertension. Exp Therap Med 2012;45:839-843. 